\title{
Skin metastasis as incidental finding in follicular epithelium derived - thyroid cancer
}

\author{
Florica SANDRU ${ }^{1,2}$, Ana VALEA ${ }^{3,4}$, Simona Elena ALBU ${ }^{2,5}$, Mihai Cristian DUMITRASCU ${ }^{2,5}$, \\ Adina GHEMIGIAN ${ }^{2,6}$, Ana Maria Alexandra STANESCU², Mara CARSOTE ${ }^{2,6}$ \\ ${ }^{1}$ Elias Emergency University Hospital, Bucharest, Romania \\ 2"Carol Davila" University of Medicine and Pharmacy, Bucharest, Romania \\ ${ }^{3}$ Clinical County Hospital, Cluj-Napoca, Romania \\ 4"Iuliu Hatieganu" University of Medicine and Pharmacy, Cluj-Napoca, Romania \\ ${ }^{5}$ Emergency University Hospital, Bucharest, Romania \\ 6"C.I. Parhon" National Institute of Endocrinology, Bucharest, Romania
}

\begin{abstract}
Skin metastases are not typical. Malignancies like mammary cancer (most frequent in females) and pulmonary neoplasia (most frequent in males) represent the majority and exceptional findings are in those originating from thyroid, prostate, ovaries and oesophagus, usually in advanced, generally disseminated stages, with a poor prognosis. It may be found more often in elderly patients. We aim to present some practical aspects of skin metastases in thyroid cancer that originates from follicular thyroid epithelium. This is a brief literature review. The level of evidence is poor since most data is provided from cases reports. Cutaneous malignant lumps are rarely the first sign of disease, mostly associating a cancer relapse. The location varies from neck and head (majority) to exceptional sites as chest wall and of variable rate for scalp. Underling neck muscle or Meckel's cave metastasis may be associated. The lesion is usually a lump of medium to small size, sometimes of papular appearance, without local pain (but depends on the site); it may associate erythema. The diagnosis is difficult unless an index of suspicion is positive (in which case whole body radioiodine scintigram may be useful). Biopsy and histological report are essential for diagnosis especially in cases without an evident connection to a prior/synchronous thyroid malignancy. Knowing the exceptional prevalence, the need for awareness in this particular topic is connected with a multidisciplinary daily practice.
\end{abstract}

Keywords: skin metastases, thyroid cancer, thyroid nodule, follicular cancer

Abbreviations: $\mathrm{I}$ = iodine

\section{INTRODUCTION}

Primary thyroid cancer includes differentiated subgroup like follicular and papillary as well as anaplastic in addition to C-cells associated cancer of medullar type $(1,2)$. The most aggressive types are anaplastic and medullar; the risk of skin secondary spreading is generally low $(3,4)$. In many cases the detection of a cutaneous lump is incidental or incidentally related to a prior primary thyroid ma- 
lignancy $(4,5)$. The thyroid cancer represents the most frequent endocrine cancer but in general population the prevalence is low, accounting less than $1 \%$ of all cancers $(1,2,3)$.

On the other hand, skin as site of metastases is not typical (4). Malignancies like mammary cancer (most frequent in females), melanoma and pulmonary neoplasia (most frequent in males) represent the majority of neoplasia able to spread at cutaneous level despite the fact that skin is not actually a traditional region of secondary implant (4). Other cancers have been cited on this list with a lower incidence of skin involvement like those originating from thyroid, prostate, ovaries and oesophagus (4). This condition arises from carcinomas, usually in advanced, generally disseminated stages (4). It represents the hallmark of poor prognosis (4). Some cases series also suggested that elderly patients seem more frequent but the statistical data is not very convincing due to the rarity of condition (4).

\section{AIM}

We aim to present some practical aspects involving the risk of skin metastases in thyroid cancer that originates from follicular thyroid epithelium.

\section{METHOD}

This is a brief literature review. The main research tool is Pub Med. A number of 30 papers are included. The level of evidence is based on cases reports and short series. Some articles of narrative review type are also cited.

\section{GENERAL PRESENTATION}

\section{Thyroid cancer}

Follicular and papillary cancers represent differentiated thyroid malignancies, the most frequent subgroup of thyroid cancer $(6,7)$. They are derived by follicular epithelial cells (as well as anaplastic subtype) $(6,7)$ Their detection starts from a suspected nodule either isolated or associating multinodular goitre based on clinical and/or endocrine examination $(8,9)$ The next logical step of evaluation is thyroid ultrasound, the best screening tool $(8,9,10)$ (Figure 1 ). Typical evolution of differentiated thyroid cancer is slow with a good prognosis $(6,7)$. Thyroidectomy is the first line of approach and lifelong levothyroxine substitution is necessary in cases with total thyroid removal in association with $I^{131}$ radioiodine therapy $(6,7)$. Local remnants or disease relapse as well as distant metastases usually are responsive to high dose of radioiodine therapy, re-surgery is less frequent indicated $(6,7)$. The prognostic marker is blood thyroglobulin in patients who suffered a total thyroidectomy after the adjustment of its values if positive blood anti-thyroglobulin antibodies are identified $(6,7)$. The detection of metastases associating radioiodine uptake capacity is based on whole body scintigram but the extra-thyroid ${ }^{131}$ uptake may also be found in so called "benign" conditions, for instance, at the level of normal liver, muscles, kidneys and even skin (6).

\section{Skin metastases}

Follicular thyroid cancer disseminates through both pathways (blood and lymph) not only via lo-

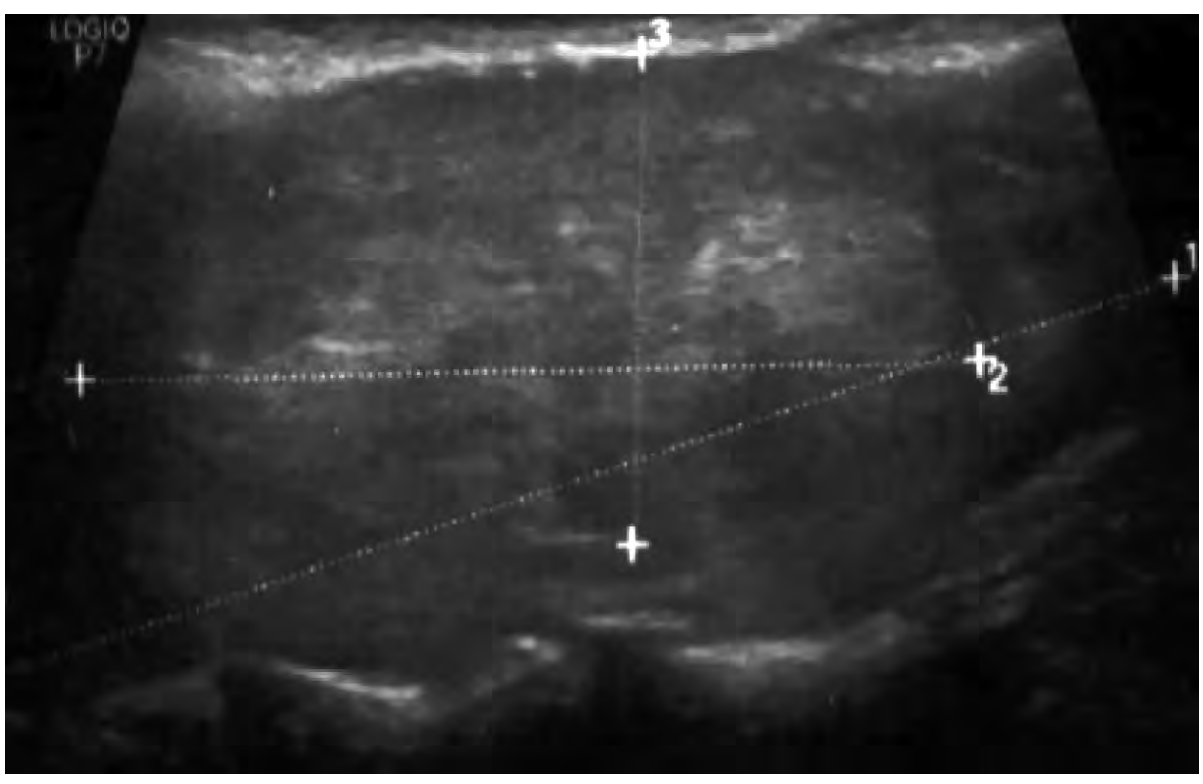

FIGURE 1. Thyroid ultrasound on a 36-year old female: longitudinal section of the right lobe (longitudinal diameter of $5.7 \mathrm{~cm}$ ) pointing a macronodule of 3.8 by 2.9 by $2.5 \mathrm{~cm}$ (centimetre). The patient presented rapidly developing goitre within weeks and a malignancy was suspected. Total thyroidectomy was performed and an follicular adenoma with hyperplasic epithelium was identified of micro-follicular and trabecular sub-type 
cal invasion $(1,2)$. Hematogenous route typically involves pulmonary and osseous metastases $(1,2)$. The local spreading involves cervical lymph nodes (6). The sentinel node is located within central compartment (levels VI and VII); the second station is lateral compartment (levels II, III, IV, and V) followed by contralateral neck region (6). The rarest secondary sites of thyroid cancer involvement that have been cited are at mammary level, renal area as well as pancreas, adrenals, cerebral, ovarian, parotids, and teguments $(11,12,13)$. Cutaneous location varies from neck and head (majority) to exceptional sites as chest wall and of variable incidence for scalp $(11,12,14,15)$. Underling neck muscle or Meckel's cave in association with local teguments has also been reported $(15,16)$.

The skin lesion is usually a lump of medium to small size, sometimes of papular appearance, without local pain (but depends on the site); it may associate local erythema $(11,12)$.

The diagnosis is difficult to establish unless an index of suspicion is positive $(17,18,19)$. Reports of skin metastases include subjects with follicular and papillary subtypes and also papillary with follicular variant or anaplastic forms among follicular epithelium derived malignancies $(11,12,20,21)$.

Biopsy and consecutive histological report are essential for diagnosis in cases without an evident connection to the thyroid malignancy (16). In thyroid neoplasia, skin metastases are rarely seen as the first sign of disease, but they may represent the sign of relapse (14).

If a metastasis from thyroid cancer is considered, a whole body radioiodine $\left(\mathrm{I}^{123}\right.$ or $\left.\mathrm{I}^{131}\right)$ is useful for the cases with thyroid hormone local production as seen most probably in follicular cancer (17). The follicular cancer metastases might display typical thyroid activity thus a whole body radioiodine scintigram points out their connection with the primary lesion (17). However, except for differentiated types, the other thyroid cancers are not necessarily suggested by this functional imaging technique thus the pathological report becomes essential for aetiology confirmation (17).

Other reports include as potential panel of investigations: synchronous identification of the same mutation like BRAF in thyroid neoplasia and skin lump that might be a valuable clue for their potential connection (12). Also, the use of immunohistochemistry marker PAX-8 applies for spindle cell component of anaplastic thyroid cancer/skin metastases as a differential diagnosis tool from others malignancies containing spindle cells (21). If isolated or radioiodine refractory, surgical removal of cutaneous metastasis is indicated (18).

\section{DISCUSSION}

The limits of the current subject are mostly related to lack of clear evidence based medicine data because of exceptional low incidence. Which is the real prevalence of skin metastases in epithelium derivate thyroid cancers is still a matter of debate. Also, which type of thyroid malignancy is more exposed to this form of evolution is still an open issue. No particular constellation of risk factors has been reported for the cutaneous secondary spreading, except probably for advance age and disease $(6,11)$.

\section{Incidental findings}

The presence of newly detected skin lump may be incidental and the connection with thyroid malignancy may not be evident at admission $(14,15,16)$. Lately, incidental findings of solid, cystic or mix consistence, are not only clinically, but also radiological detected and their identification has an explosive incidence during last decades $(22,23,24)$. In endocrinology, "thyroid incidentaloma" expression is mostly displayed by "thyroid nodule" expression for daily practice while for pituitary and adrenal glands the term of 'incidentaloma" is largely used $(22,25,26)$. If tumour removal is less indicated in mentioned pituitary and adrenal incidentalomas, surgery for an incidental thyroid nodule is recommended depending on complex risk stratification strategy of approach $(1,22,27)$. Incidental finding of a skin lump originating from a thyroid cancer remains an exceptional scenario $(28,29,30)$. Whole body imagery evaluation may show the general metastatic context if positive or it may suggest the thyroid origin especially in patients with prior thyroidectomy and a certain disease free interval $(28,29,30)$. Overall, histological report, radioiodine uptake at scintigraphy or high circulating thyroglobulin of otherwise unexplained source are the best assessments for an adequate diagnosis and further therapy even the general prognosis is considered severe in this cases $(28,29,30)$.

\section{CONCLUSION}

Knowing the exceptional prevalence of thyroid cancer-related skin metastases, the need for awareness is connected with a multidisciplinary daily practice.

Conflict of interest: none declared Financial support: none declared 


\section{REFERENCES}

1. Haugen BR, Sawka AM, Alexander EK, Bible KC, Caturegli P, Doherty GM, Mandel SJ, Morris JC, Nassar A, Pacini F, Schlumberger M, Schuff K, Sherman SI, Somerset H, Sosa JA, Steward DL, Wartofsky L, Williams MD. American Thyroid Association Guidelines on the Management of Thyroid Nodules and Differentiated Thyroid Cancer Task Force Review and Recommendation on the Proposed Renaming of Encapsulated Follicular Variant Papillary Thyroid Carcinoma Without Invasion to Noninvasive Follicular Thyroid Neoplasm with Papillary-Like Nuclear Features. Thyroid. 2017; 27(4):481-483.

2. Haugen BR, Alexander EK, Bible KC, Doherty GM, Mandel SJ, Nikiforov YE, Pacini F, Randolph GW, Sawka AM, Schlumberger M, Schuff KG, Sherman SI, Sosa JA, Steward DL, Tuttle RM, Wartofsky L. 2015 American Thyroid Association Management Guidelines for Adult Patients with Thyroid Nodules and Differentiated Thyroid Cancer: The American Thyroid Association Guidelines Task Force on Thyroid Nodules and Differentiated Thyroid Cancer. Thyroid. 2016; 26(1):1-133.

3. Haugen BR. 2015 American Thyroid Association Management Guidelines for Adult Patients with Thyroid Nodules and Differentiated Thyroid Cancer: What is new and what has changed? Cancer. 2017; 123(3):372-381.

4. Ruiz SJ, AI Salihi S, Prieto VG, Nagarajan $P$, Tetzlaff MT, Curry JL, Ivan D, TorresCabala CA, Aung PP. Unusual cutaneous metastatic carcinoma. Ann Diagn Pathol. 2019; 43:151399.

5. Carsote M, Valea A, Dumitru N, Terzea D, Petrova E, Albu S, Buruiana A, Ghemigian A. Metastases in daily endocrine practice. Archives of Balkan Medical Union. 2016; 51(4):476-480.

6. Palaniswamy SS, Subramanyam P. Unusual Sites of Metastatic and Benign I 131 Uptake in Patients with Differentiated Thyroid Carcinoma. Indian J Endocrinol Metab. 2018; 22(6):740-750.

7. Ghemigian A, Carsote M, Valea A, Gheorghisan-Galateanu AA, DanciulescuMiulescu R, Paun DL. Adult women with papilary thyroid cancer. Revista Medicala Romana 2019; 66; 2:162-165.

8. Dumitru N, Ghemigian A, Carsote M, Albu SE, Terzea D, Valea A. Thyroid nodules after initial evaluation by primary health care practitioners: An ultrasound pictorial essay. Archives of the Balkan Medical Union. 2016; 51(3):434-438.

9. Ghemigian A, Carsote M, Petrova E, Valea A, Dumitru N, Cocolos A. Detection of thyroid nodules by routine ultrasound. Practica Medicala. 2017; 12;4(53):224-9.

10. Vasiliu C, Albu SE, Carsote M, Valea A, Ghemigian A, Gheorghisan-Galateanu AA. Thyroid nodules: a puzzle in gynecoogical endocrinology. Archives of the Balkan Medical Union. 2019;54(2):363-367.

11. Li T, Ma Z, Lu C, Zhou Q, Feng Z, Wu X, Luo Y, Li D, Cheng X, Liu X. Chest wall lymph node metastasis from follicular thyroid carcinoma: A rare case report. Diagn Pathol. 2019; 14(1):130.

12. Monti E, Dono M, Gonella E, Spina B, Pitto F, Petrogalli F, Conte L, Ambrosetti E, Minuto MN, Ansaldo GL, Morbelli S, Zupo S, Giusti M. An H-TERT Mutated Skin Metastasis as First Occurrence in a Case of Follicular Thyroid Carcinoma. Front Endocrinol (Lausanne). 2019; 10:513.

13. Blažeković I, Jukić T, Granić R, Punda M, Franceschi M. An Unusual Case of Papillary Thyroid Carcinoma lodine-131 Avid Metastasis to the Adrenal Gland. Acta Clin Croat. 2018; 57(2):372-376.

14. Lira MLA, Almeida MA, Reis-Feroldi MM, Rocha JA. Follicular thyroid carcinoma metastatic to skin: A small papule and a big diagnostic change. An Bras Dermatol. 2019; 94(1):76-78.

15. Phelan PS, Mull JL, Rajput MZ, Musiek AC. Concurrent metastases of papillary thyroid carcinoma to the scalp and Meckel's cave. BMJ Case Rep. 2018 Jun 17; 2018.

16. Sindoni A, Gobitti C, Sulfaro S, Giacomarra $\mathrm{V}$, Borsatti $\mathrm{E}$. Unusual presentation of recurrent papillary thyroid microcarcinoma with neck muscles and skin dissemination. Hormones (Athens). 2018; 17(4):589-591.

17. Soylu S, Arikan AE, Teksoz S, Ozcan M, Bukey Y. Skin metastasis on the neck: an unusual presentation of recurrence of papillary thyroid carcinoma. Gland Surg. 2017; 6(5):594-597.

18. Aria A, Chen L, Rosenbaum LE, Migden MR. Mohs Micrographic Surgery for the Treatment of Cutaneous Metastases in a Patient With Papillary Thyroid Carcinoma. Dermatol Surg. 2018; 44(11):1457-1459.

19. Rodríguez-Lomba E, Molina-López I, Parra-Blanco V, Suárez-Fernández R, Ciudad-Blanco C. Cutaneous implantation of papillary thyroid carcinoma secondary to percutaneous ethanol injection into nodal metastasis. J Eur Acad Dermatol Venereol. 2018; 32(1):e11-e13.

20. Márquez García A, Ferrándiz Pulido L, Ríos-Martín JJ, Camacho Martínez FM. Cutaneous metastases on the head and neck from a papillary thyroid carcinoma, follicular variant. Actas Dermosifiliogr. 2016; 107(1):83-5.

21. Danialan $R$, Tetzlaff MT, Torres-Cabala CA, Mays SR, Prieto VG, Bell D, Curry JL. Cutaneous metastasis from anaplastic thyroid carcinoma exhibiting exclusively a spindle cell morphology. A case report and review of literature. J Cutan Pathol. 2016; 43(3):252-7.

22. Gheorghisan-Galateanu AA, Carsote $M$, Valea A. Incidentaloma: from general practice to specific endocrine frame. J Pak Med Assoc. 2017; 67(6):917-922.

23. Poiana C, Chirita C, Carsote M, Hortopan D, loachim D, Corneci CM, Stanescu B. Adrenal and Pituitary Incidentalomas in a Case of Cushing's Syndrome. Chirurgia 2013; 6(108):886-891.

24. Poiana C, Carsote M, Chirita C, Terzea D, Paun S, Beuran M. Giant adrenal cyst: case study, J Med Life 2010; 3(3):308-313.

25. Gheorghiu M, Hortopan D, Dumitrascu A, Caragheorgheopol A, Stefanescu A, Trifanescu R, Niculescu D, Baciu I, Carsote M, Poiana C, Badiu C, Coculescu M. Age-related endocrine tumors: Nonfunctioning adrenal tumors as compared to pituitary adenomas. Acta Endocrinologica, 2009; V(3):371-384

26. Carsote M, Chirita C, Dumitrascu A, Fica S, Poiana C. Pituitary incidentalomas -How often is too often? Journal of Medicine and Life, 2009; 2(1):92-97.

27. Paduraru DN, Nica $A$, Carsote $M$, Valea $A$. Adrenalectomy for Cushing's syndrome: do's and don'ts. Journal of Medicine and Life. 2016; 4(9):334-341.

28. Bansal A, Kaur M, Narula V. Cutaneous and bone metastasis of follicular thyroid carcinoma: A case report. Tumori. 2016; 102(Suppl. 2).

29. Jehangir A, Pathak R, Aryal M, Qureshi A, Jehangir $Q$, Alweis R, Truex R, Kimmel W. Thyroid follicular carcinoma presenting as metastatic skin nodules. J Community Hosp Intern Med Perspect. 2015; 5(1):26332.

30. Nwaeze O, Obidike S, Mullen D, Aftab F. Follicular variant papillary thyroid carcinoma with a twist. Int J Surg Case Rep. 2015; 8C:107-10. 